\title{
Reduced Uptake of Oxidized Low Density Lipoproteins in Monocyte-derived Macrophages from CD36-deficient Subjects
}

\author{
Shuichi Nozaki, ${ }^{*}$ Hirokazu Kashiwagi, ${ }^{*}$ Shizuya Yamashita, ${ }^{*}$ Tsutomu Nakagawa, ${ }^{*}$ Bernd Kostner, ${ }^{*}$ Yoshiaki Tomiyama, \\ Atsuyuki Nakata, ${ }^{\star}$ Masato Ishigami, ${ }^{\star}$ Jun-ichiro Miyagawa, ${ }^{\star}$ Kaoru Kameda-Takemura, ${ }^{\star}$ Yoshiyuki Kurata, ${ }^{\ddagger}$ \\ and Yuji Matsuzawa* \\ * Second Department of Internal Medicine, Osaka University Medical School; and ${ }^{\ddagger}$ Department of Blood Transfusion, Osaka University \\ Hospital, Suita, Osaka 565, Japan
}

\begin{abstract}
To clarify the physiological roles of CD36 as an oxidized low density lipoprotein (OxLDL) receptor, we analyzed the monocyte-derived macrophages from normal and two CD36-deficient subjects, since we identified the molecular abnormalities (Kashiwagi, H., Y. Tomiyama, Y. Kosugi, M. Shiraga, R. H. Lipsky, Y. Kanayama, Y. Kurata, and Y. Matsuzawa. 1994. Blood. 83:3545-3552; and Kashiwagi, H., Y. Tomiyama, S. Honda, S. Kosugi, M. Shiraga, N. Nagao, S. Sekiguchi, Y. Kanayama, Y. Kurata, and Y. Matsuzawa. 1995. J. Clin. Invest. 95:1040-1046). Scatchard analysis of ${ }^{125}$ I-OxLDL binding showed a linear plot and the maximum binding was lower by $\sim 40 \%$ in the macrophages from subjects with CD36 deficiency than those from normal controls. Competition studies showed that the uptake of ${ }^{125} \mathrm{I}-\mathrm{OxLDL}$ was suppressed by OKM5, an antibody against CD36, by $53 \%$ in normal control macrophages, but not in the CD36deficient macrophages. After incubation with OxLDL for $24 \mathrm{~h}$, cholesteryl ester mass accumulation was reduced by $\sim 40 \%$ in the macrophages from CD36-deficient subjects than those from normal controls. These results suggest that CD36 is one of the physiological receptors for OxLDL. Since specific binding of OxLDL was only reduced by $\sim 40 \%$ in spite of the complete deficiency of CD36, several other receptors also may have some role in OxLDL uptake. Further studies will be needed to assess the quantitative role of CD36 in foam cell formation in vivo. (J. Clin. Invest. 1995. 96:1859-1865.) Key words: macrophage • oxidized LDL receptor • CD36 deficiency • acetyl LDL receptor • foam cell formation
\end{abstract}

\section{Introduction}

Foam cell formation is a characteristic feature of atherosclerotic lesions. Previous studies suggested that macrophages play an

\footnotetext{
A portion of this work was presented at the 10th International Symposium on Atherosclerosis in Montreal, Canada on 10 October, 1994 and a meeting of the American Heart Association in Dallas, TX on 15 November, 1994.

Address correspondence to Shuichi Nozaki, Second Department of Internal Medicine, Osaka University Medical School, 2-2 Yamadaoka, Suita, Osaka 565, Japan. Phone: 81-6-879-3732; FAX: 81-6-879-3739. Received for publication 15 February 1995 and accepted in revised form 19 June 1995.
}

J. Clin. Invest.

(C) The American Society for Clinical Investigation, Inc.

0021-9738/95/10/1859/07 \$2.00

Volume 96, October 1995, 1859-1865 important role in foam cell formation (1-4). Goldstein et al. first reported that LDL modified chemically by acetylation is incorporated into macrophages through scavenger receptors, resulting in the formation of lipid-laden foam cells (5). Kodama et al. identified one of the scavenger receptors by using acetylLDL (AcLDL) ${ }^{1}$ as a ligand $(6,7)$. However, it seems unlikely that acetylation of LDL would occur in vivo. Steinberg et al. found that the incubation of LDL with endothelial cells produced modified LDL, which was later found to be composed of oxidized LDL (OxLDL) $(8,9)$. OxLDL is now considered to be one of the modified LDLs that may exist in vivo. A number of recent studies have established the role of OxLDL in atherogenesis $(10-12)$. OxLDL was reported to bind to the AcLDL receptor, while several investigators suggested that the OxLDL receptors other than AcLDL receptor found by Kodama et al. may be present (13-15).

CD36 is a glycoprotein of $88 \mathrm{kD}$ and is expressed on platelets, monocytes, and capillary endothelial cells (16). The physiological function of CD36 has not been well characterized although it was proposed to be a receptor for both thrombospondin and collagen or to mediate cytoadherence of plasmodium falciparum parasitized erythrocytes (17-20). From the research on the subjects refractory to HLA-matched platelets transfusion (21-24), Kashiwagi et al. have identified the subjects whose platelets and monocytes lack CD36, and clarified three types of gene abnormalities (substitution of Pro ${ }^{90}$ by Ser, deletion of two bases in exon 5, and insertion of one base in exon 10; Kashiwagi, H., Y. Tomiyama, S. Nozaki, S. Honda, H. Mizutani, S. Kosugi, M. Shiraga, N. Nagao, Y. Kanakura, Y. Kurata, and Y. Matsuzawa, manuscript in submission) $(25,26)$. All these abnormalities result in the absence of CD36 expression on the cell surface. Recently, Endemann et al. reported (27) that CD36 may be a novel receptor for OxLDL based on the results of experiments using CD36-transfected cells. In the current study, we aimed to clarify the physiological role of CD36 as an oxidized LDL receptor by analyzing the binding capacity of monocyte-derived macrophages from subjects with CD36 deficiency in comparison with those from normal controls. We demonstrate that the uptake of OxLDL is markedly reduced in macrophages from CD36-deficient subjects and that CD36 may be one of the physiological receptors for OxLDL in vivo.

\section{Methods}

Subjects. Two female subjects (case 1 and case 2) with anti-Nak ${ }^{\mathrm{a}}$ antibodies were identified by screening with platelet-specific antibodies

1. Abbreviations used in this paper: AcLDL, acetylated LDL; CE, cholesteryl ester; OxLDL, oxidized LDL. 
at the Osaka Red Cross Blood Center and the Department of Blood Transfusion at Kinki University Hospital (Osaka, Japan). Case 1 is 50yr-old and case 239 -yr-old, respectively. They are apparently healthy and have neither suffered from coronary heart disease nor presented any symptoms of easy bleeding. They do not have any family history of coronary heart disease or other atherosclerotic cardiovascular diseases. Immunofluorescent flow cytometry demonstrated that their platelets and monocytes lacked cell surface CD36 (see Fig. 1). Their gene abnormalities were the same and consisted of compound heterozygosity for a twobase deletion in exon 5 and one base insertion in exon 10 (Kashiwagi, H., Y. Tomiyama, S. Nozaki, S. Honda, H. Mizutani, S. Kosugi, M. Shiraga, N. Nagao, Y. Kanakura, Y. Kurata, and Y. Matsuzawa, manuscript in submission) (26).

Immunofluorescent flow cytometry. Immunofluorescent flow cytometric analysis was performed by using a mouse monoclonal antibody against CD36, (OKM5); (Ortho Diagnostic System Inc., Raritan, NJ) (24). Mononuclear cells were isolated by density gradient centrifugation of heparinized peripheral blood using Ficoll-paque. $20 \mathrm{ml}$ of blood (anticoagulated with $10 \mathrm{U} / \mathrm{ml}$ heparin) was layered over $10 \mathrm{ml}$ of Ficollpaque and centrifuged at $1,000 \mathrm{~g}$ for $30 \mathrm{~min}$. Mononuclear cells (2 $\times 10^{5}$ in $100 \mu \mathrm{l}$ ) were incubated with FITC-conjugated OKM5 (final concentration: $2.5 \mu \mathrm{g} / \mathrm{ml}$ ) or FITC-conjugated mouse IgG1 (final concentration: $2.5 \mu \mathrm{g} / \mathrm{ml}$ ) for $30 \mathrm{~min}$ at $4^{\circ} \mathrm{C}$ and assayed on a FACScan ${ }^{\circledR}$ (Becton Dickinson and Co., Mountain View, CA) as previously reported (24). Appropriate cell fractions for the analysis of monocytes were selected by a gating method with a two-dimensional display of forward scatter and side scatter of analyzed cells.

Isolation of human monocyte-derived macrophage. Mononuclear cells were isolated as described above. Mononuclear cells were plated at a density of $2 \times 10^{6}$ cells in a 16-mm well (Primaria brand, Falcon Labware; Becton, Dickinson and Co.) in RPMI-1640 containing 10\% ( vol $/ \mathrm{vol}$ ) human type-AB serum. After $4 \mathrm{~h}$ of incubation at $37^{\circ} \mathrm{C}$ in $5 \%$ $\mathrm{CO}_{2}$, nonadherent cells were removed. Monocyte-derived macrophages cultured for 12-14 $\mathrm{d}$ were used for the assays.

Lipoproteins. Human LDL (density, $1.019-1.063 \mathrm{~g} / \mathrm{ml}$ ) was isolated by ultracentrifugation from the plasma of healthy volunteers as previously reported (28). LDL was acetylated with repeated additions of acetic anhydride $(5,29)$. Oxidized LDL was prepared by incubating LDL with $5 \mu \mathrm{M} \mathrm{CuSO}_{4}$ for $24 \mathrm{~h}$. These lipoproteins were radioiodinated using the iodine monochloride method as previously reported $(30,31)$. OxLDL was also conjugated with FITC according to the method previously reported by Tomiyama et al. (32). In brief, OxLDL solution $(1.7 \mathrm{mg} / \mathrm{ml})$ was dialyzed against carbonate buffer $\left(0.16 \mathrm{M} \mathrm{Na}_{2} \mathrm{CO}_{3}\right.$, $0.33 \mathrm{M} \mathrm{NaHCO}_{3}, \mathrm{pH}$ 9.5). FITC (Sigma Chemical Co., St. Louis, MO) was dissolved with dimethylsulfoxide to give a concentration of $10 \mathrm{mg} /$ $\mathrm{ml} .200 \mu \mathrm{g}$ FITC per milligram OxLDL protein was added to the OxLDL solution. The mixture was incubated for $4 \mathrm{~h}$ with stirring in the dark at room temperature, and then dialyzed against PBS overnight.

Assays for binding, cell association, and degradation of $O x L D L$. Binding assays of ${ }^{125} \mathrm{I}$-OxLDL in macrophages from normal and CD36deficient subjects were performed at $4^{\circ} \mathrm{C}$ for $1 \mathrm{~h}$. After washing with PBS three times, the cells were dissolved in $1.0 \mathrm{ml}$ of $0.1 \mathrm{~N} \mathrm{NaOH}$ and the radioactivity was measured by a gamma counter as binding of lipoprotein. The protein concentration of the dissolved aliquot of macrophages was determined by the method of Lowry et al. (33). Cell association and degradation of ${ }^{125} \mathrm{I}-\mathrm{OxLDL}$ in macrophages from normal and CD36-deficient subjects were also determined after $4 \mathrm{~h}$ of incubation at $37^{\circ} \mathrm{C}$ with ${ }^{125} \mathrm{I}$-OxLDL and 40 -fold excess amounts of unlabeled lipoproteins. After washing with PBS three times, the cells were dissolved in $1.0 \mathrm{ml}$ of $0.1 \mathrm{~N} \mathrm{NaOH}$ and the radioactivity was measured as cell association of lipoproteins. Lipoprotein degradation was quantitated by measurement of trichloroacetic acid-soluble noniodide radioactivity in the medium after incubation (34). For degradation analysis, noncell degradation was subtracted from the data.

Assay of cellular cholesteryl ester (CE) content in macrophages. Macrophages were cultured for $12 \mathrm{~d}$. On the 13th day AcLDL ( $50 \mu \mathrm{g} /$ $\mathrm{ml}$ ) or OxLDL ( $50 \mu \mathrm{g} / \mathrm{ml})$ was added to the medium and the cells were

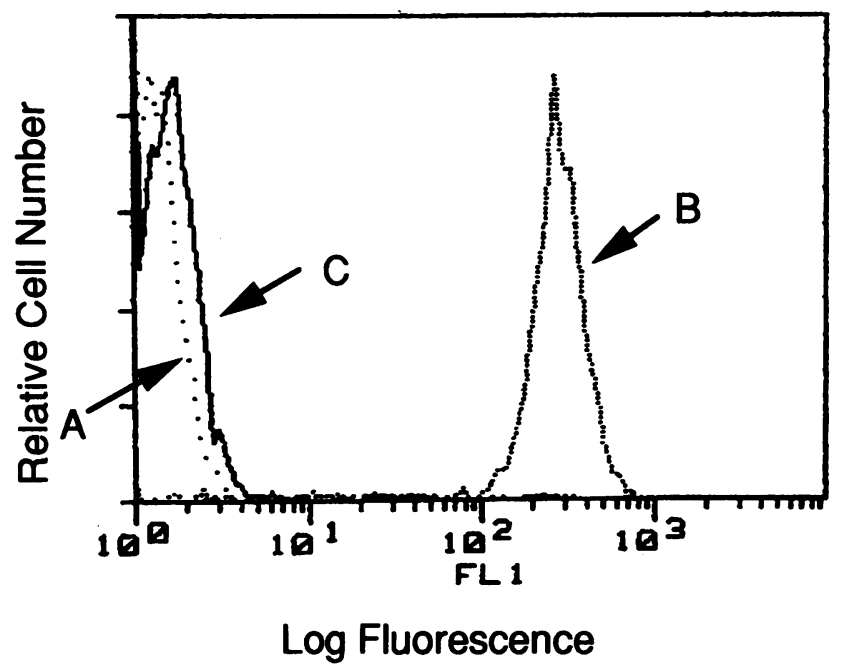

Figure 1. Flow cytometric analysis for surface expression of CD36 on monocytes from a CD36-deficient subject and a normal control. $(A)$ Control monocytes incubated with control FITC-conjugated IgG1. (B) Control monocytes incubated with FITC-conjugated OKM5. $(C)$ CD36deficient monocytes incubated with FITC-conjugated OKM5.

incubated for $24 \mathrm{~h}$. The incubation medium was then discarded and the cellular lipids were extracted by incubating the cells with hexane/ isopropanol $(3: 2, \mathrm{vol} / \mathrm{vol})$ for $30 \mathrm{~min}$ at room temperature. The cholesterol content of the supernatant was determined by the enzymatic, fluorometric method by Heider and Boyett with minor modifications (35, 36). Briefly, the lipid extract was dried under nitrogen and dissolved in $180 \mu \mathrm{l}$ of isopropanol. $30 \mu \mathrm{l}$ of the supernatant was then added to $0.4 \mathrm{ml}$ of an enzyme mixture containing $0.16 \mathrm{U} / \mathrm{ml}$ cholesterol oxidase and $60 \mathrm{U} / \mathrm{ml}$ cholesterol esterase. The reaction mixtures for measuring free cholesterol and those for total cholesterol were incubated at $37^{\circ} \mathrm{C}$ for 1 and $2 \mathrm{~h}$, respectively, followed by the addition of $0.81 \mathrm{ml}$ of 0.5 $\mathrm{N} \mathrm{NaOH}$ to terminate the reaction. Fluorescence intensity was measured with excitation at $310 \mathrm{~nm}$ and emission at $407 \mathrm{~nm}$. The mass of CE was calculated by subtracting free cholesterol from total cholesterol. After lipid extraction, the cellular protein was dissolved in $1.0 \mathrm{ml}$ of 0.1 $\mathrm{N} \mathrm{NaOH}$ and the protein concentration was determined by the method of Lowry et al.

\section{Results}

Fig. 1 shows a representative pattern of the flow cytometric analysis for surface expression of CD36 on monocytes. OKM5, an antibody against CD36, bound to the monocytes obtained from control subjects, while it did not bind to the monocytes from CD36-deficient subjects (Fig. 1). Expression of CD36 on monocyte-derived macrophages was investigated by an immunohistochemical analysis using FITC-conjugated OKM5. As shown in Fig. 2, expression of CD36 was demonstrated only in control monocyte-derived macrophages incubated with FITCconjugated OKM5. No immunofluorescence was detected on the macrophages from CD36-deficient subjects. Then, the binding of FITC-conjugated OxLDL to CD36 deficient and control monocytes was analyzed by FACScan ${ }^{\circledR}$. The binding capacity of OxLDL to CD36-deficient monocytes was reduced and $\sim 23 \%$ of that to control monocytes when it was calculated as a mean fluorescence intensity.

By using macrophages, we studied the binding, cell associa- 

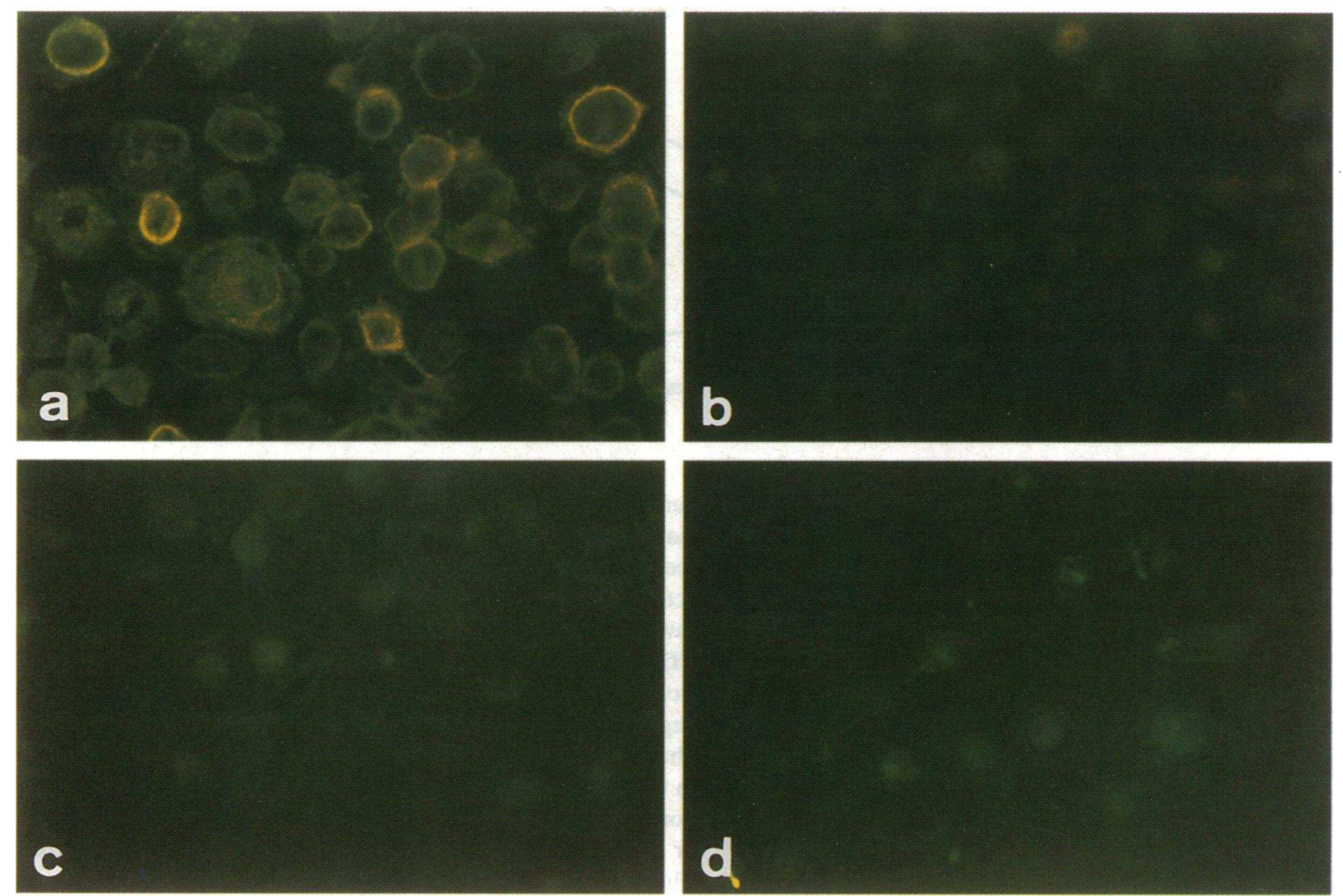

Figure 2. Fluorescent micrographs of expression of CD36 in normal and CD36-deficient monocyte-derived macrophages. Isolated monocytes were cultured in RPMI-1640 supplemented with 10\% human type-AB serum on an 8-well polystyrene chamber slide (Lab-Tek; Nunc, Inc., Naperville, IL) for $12 \mathrm{~d}$. Cultured monocyte-derived macrophages were washed in $0.01 \mathrm{M}$ PBS containing $1 \% \mathrm{BSA}$ for $5 \mathrm{~min}$ at $4^{\circ} \mathrm{C}$, and incubated with FITC-conjugated mouse monoclonal antibody to CD36 (OKM5) or FITC-conjugated normal mouse IgG1 for the negative control for $30 \mathrm{~min}$ at $4^{\circ} \mathrm{C}$. After fixation with $4 \%$ paraformaldehyde dissolved in $0.1 \mathrm{M}$ phosphate buffer for $5 \mathrm{~min}$ at $4^{\circ} \mathrm{C}$, the specimens were mounted with aqueous mounting medium (Perma Fluor; IMMUNON, Pittsburgh, PA). (a) Control monocyte-derived macrophages incubated with FITC-conjugated OKM5. (b) Control monocyte-derived macrophages incubated with FITC-conjugated control IgG1. (c) CD36 deficient monocyte-derived macrophages incubated with FITC-conjugated OKM5. (d) CD36-deficient monocyte-derived macrophages incubated with FITC-conjugated control IgG1.

tion, and degradation of Ox-LDL. Fig. 3 shows representative data of specific binding of ${ }^{125}$ I-OxLDL to macrophages. Scatchard analysis showed that the maximum binding of ${ }^{125} \mathrm{I}-\mathrm{OxLDL}$ to macrophages from CD36-deficient subjects was $\sim 40 \%$ lower than that from controls. The $K_{\mathrm{d}}$ was almost the same in both monocyte-derived macrophages $(11.3 \mu \mathrm{g} / \mathrm{ml}$ for CD36 deficiency and $7.4 \mu \mathrm{g} / \mathrm{ml}$ for the control, respectively). As shown in Fig. 4, both cell association and degradation of
A

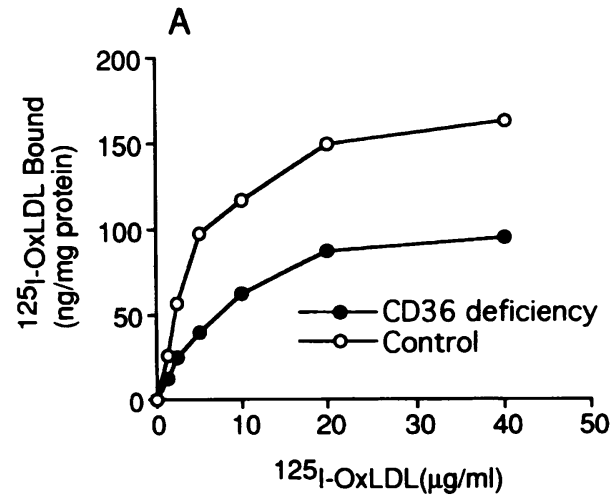

B

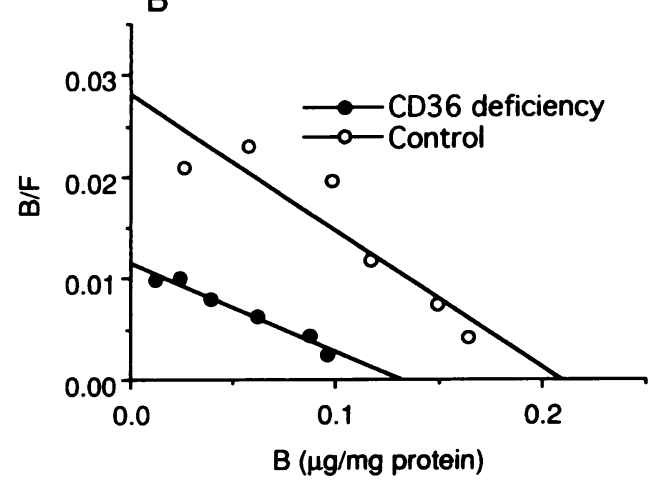

Figure 3. Binding of ${ }^{125} \mathrm{I}-\mathrm{OxLDL}$ to normal and CD36-deficient macrophages $(A)$ and Scatchard analysis of specific binding of ${ }^{125} \mathrm{I}$ OxLDL to macrophages $(B)$. Vertical bar in $A$ shows the specific binding activities of ${ }^{125} \mathrm{I}-\mathrm{OxLDL}$ to normal and CD36-deficient macrophages. CD36-deficient and normal control macrophages were incubated with indicated concentrations of ${ }^{125} \mathrm{I}-\mathrm{OxLDL}$ for $1 \mathrm{~h}$ at $4^{\circ} \mathrm{C}$ in triplicate in the presence or absence of a 40-fold excess of unlabeled OxLDL. Maximum bind-

ing of OxLDL was $0.13 \mu \mathrm{g} / \mathrm{mg}$ protein in CD36-deficient macrophages and $0.21 \mu \mathrm{g} / \mathrm{mg}$ protein in control macrophages, respectively. The specific activities were calculated by subtracting the values obtained in the presence of an excess of unlabeled OxLDL from the values obtained in the absence of unlabeled OxLDL. 


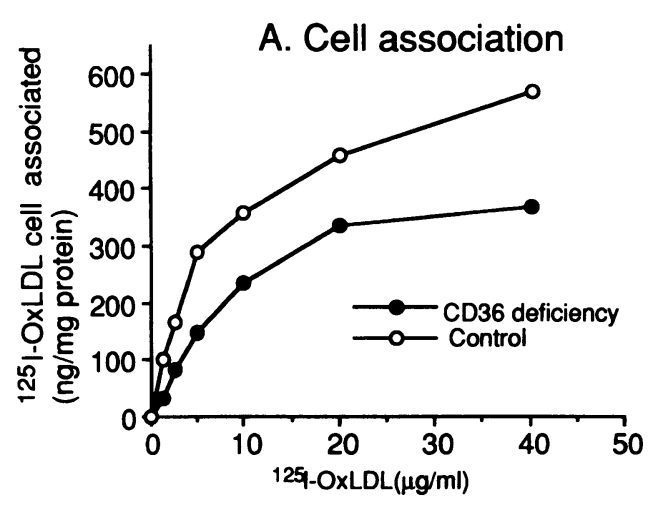

OxLDL in CD36-deficient macrophages were also lower than those in controls. These results demonstrated that monocytes and monocyte-derived macrophages from CD36-deficient subjects possessed a lesser capacity to bind or degrade OxLDL than those from control subjects.

Next, we studied the effects of two types of nonradiolabeled modified LDLs, OxLDL and AcLDL, on the cell association and degradation of OxLDL in CD36-deficient and control macrophages (Fig. 5). The effect of OKM5 was also studied. When
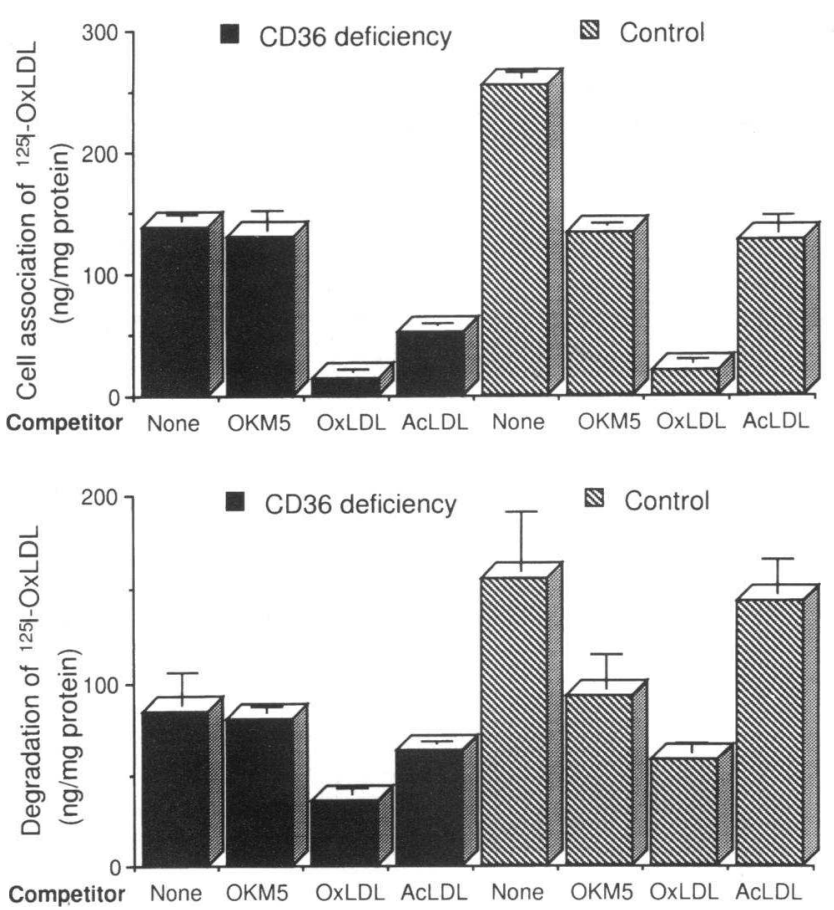

Figure 5. Effect of OKM5, unlabeled OxLDL, and unlabeled AcLDL on the cell association (top) and degradation (bottom) of ${ }^{125} \mathrm{I}-\mathrm{OxLDL}$ in macrophages from subjects with CD36 deficiency and normal subjects. OKM5 ( $4 \mu \mathrm{g} / \mathrm{ml}$ ), OxLDL (40-fold excess; $200 \mu \mathrm{g} / \mathrm{ml}$ ), and AcLDL ( 40 -fold excess; $200 \mu \mathrm{g} / \mathrm{ml}$ ) were added to the incubation medium containing $5 \mu \mathrm{g} / \mathrm{ml}$ of ${ }^{125} \mathrm{I}-\mathrm{OxLDL}$. Cells were incubated for 4 $\mathrm{h}$ at $37^{\circ} \mathrm{C}$ and cell association and degradation were measured as described in Methods. $4 \mu \mathrm{g} / \mathrm{ml}$ of OKM5 was ascertained to be adequate for the saturation of the antibody. Data are the average of four determinations and are a representative of three separate experiments in both case 1 and case 2. Data are shown as mean \pm SD.
B. Degradation

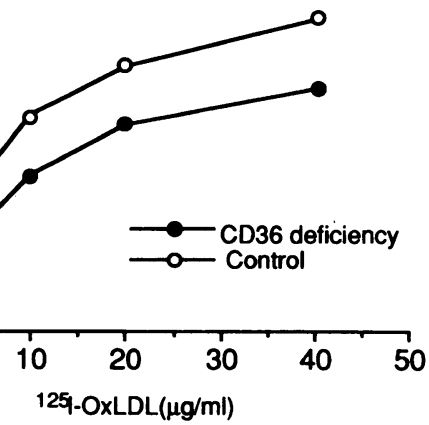

Figure 4. Cell association $(A)$ and degradation $(B)$ of ${ }^{125} \mathrm{I}-\mathrm{OxLDL}$ to normal and CD36-deficient macrophages. Vertical bars in A and B showed specific cell association and degradation of OxLDL to normal and CD36-deficient macrophages. CD36-deficient and normal control macrophages were incubated with indicated concentrations of ${ }^{125} \mathrm{I}-\mathrm{OxLDL}$ for $4 \mathrm{~h}$ at $37^{\circ} \mathrm{C}$ in triplicate in the presence or absence of a 40 -fold excess of unlabeled OxLDL. percent inhibition is calculated as a percentage of specific association/degradation (total minus nonspecific values observed in the presence of an excess of unlabeled OxLDL), both specific activities of cell association and degradation of OxLDL were lower by 47 and $51 \%$, respectively, in macrophages from the CD36-deficient subject than in macrophages from a normal control. The addition of OKM5 inhibited the cell association and degradation of OxLDL by 53 and 65\%, respectively, in macrophages from control, while it did not significantly inhibit them in CD36 deficiency. These values (53 and 65\%) nearly corresponded to the difference in specific activities of OxLDL uptake or degradation between CD36 deficiency and normal controls. These results suggest a major contribution of CD36 as an OxLDL receptor. The uptake and degradation of ${ }^{125} \mathrm{I}$-OxLDL by macrophages were suppressed only partially by the addition of Ac-LDL in both normal controls and CD36-deficient subjects.

To determine the specificity of CD36 as an OxLDL receptor, the effects of competitors on the cell association of AcLDL to macrophages were also studied in CD36-deficient and normal control macrophages. As a competitor, OKM5 and excess amounts of OxLDL and AcLDL were used. As shown in Fig. 6, the cell association of AcLDL was not significantly inhibited by OKM5 in both CD36-deficient and normal macrophages.

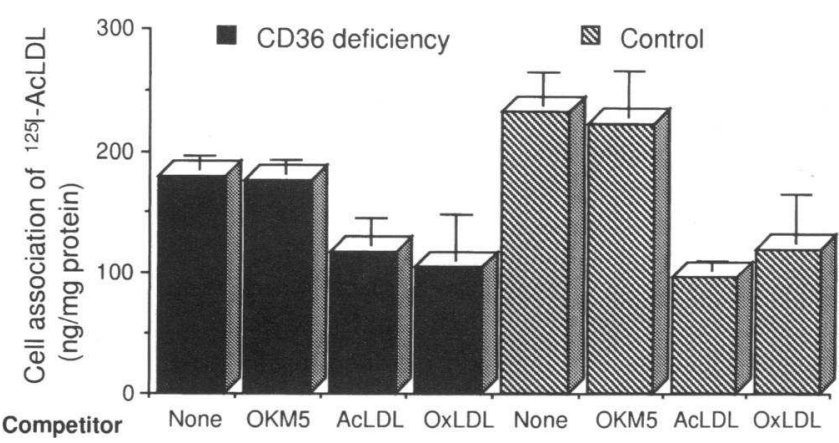

Figure 6. Cell association of AcLDL in macrophages from a subject with CD36 deficiency (case 2) and a normal subject. OKM5 (4 $\mu \mathrm{g} /$ $\mathrm{ml}$ ), OxLDL ( 40-fold excess; $200 \mu \mathrm{g} / \mathrm{ml}$ ), and AcLDL ( 40-fold excess; $200 \mu \mathrm{g} / \mathrm{ml}$ ) were added to the incubation medium containing $5 \mu \mathrm{g} / \mathrm{ml}$ of ${ }^{125} \mathrm{I}$-AcLDL. Cells were incubated for $4 \mathrm{~h}$ at $37^{\circ} \mathrm{C}$ and cell association was measured. Data are the average of quadruplicate determinations of cell association and are a representative of two separate experiments. Data are shown as mean $\pm \mathrm{SD}$. 


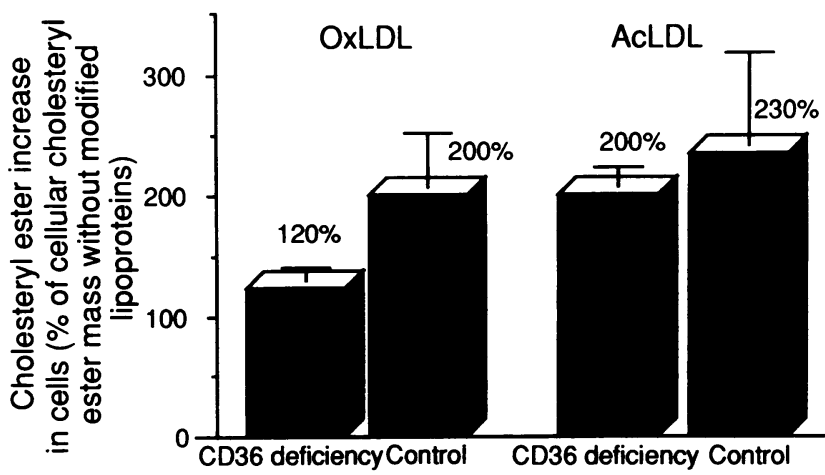

Figure 7. Cholesteryl ester accumulation in macrophages from a subject with CD36 deficiency and a normal subject. $50 \mu \mathrm{g} / \mathrm{ml}$ of OxLDL or AcLDL were incubated for $24 \mathrm{~h}$ at $37^{\circ} \mathrm{C}$. Vertical bar shows percentage of cholesteryl ester mass in macrophages incubated with OxLDL or AcLDL against cholesteryl ester mass in macrophages incubated without modified lipoproteins. Control for CD36-deficient cells represents CD36 deficient cells incubated without OxLDL or AcLDL in RPMI-1640 containing 3\% BSA and control for control cells represents control cells incubated without OxLDL or AcLDL in RPMI-1640 containing 3\% BSA for $24 \mathrm{~h}$. Data are the average of three separate determinations and are shown as mean \pm SD.

The cell association and degradation were suppressed to almost the same level by both unlabeled AcLDL and OxLDL. Specific AcLDL cell association to CD36-deficient macrophages was significantly lower by $54 \%$ than that of control macrophages.

We also examined the change in cholesterol content after incubation with OxLDL in CD36-deficient macrophages compared with that in control macrophages. Macrophages were incubated with $50 \mu \mathrm{g} / \mathrm{ml}$ OxLDL or AcLDL for $24 \mathrm{~h}$. When macrophages were incubated with OxLDL, the increase in CE accumulation was remarkably smaller in the CD36-deficient macrophages than in normal controls ( $120 \%$ increase vs $200 \%$ increase), whereas the difference in $\mathrm{CE}$ accumulation was rather small between both macrophages when incubated with AcLDL (Fig. 7).

\section{Discussion}

The current study investigated, for the first time, the capacity of binding and uptake of OxLDL in CD36-deficient macrophages. We demonstrated that CD36 plays an important role as an OxLDL receptor in human monocyte-derived macrophages.

First, we demonstrated that the macrophages from CD36 deficiency have a low capacity to bind and internalize OxLDL. Furthermore, the macrophages from CD36 deficiency accumulated a smaller amount of CE than control macrophages. These results point to the notion that reduced binding capacity for OxLDL in human monocyte-derived macrophages due to CD36 deficiency may lead to a decreased accumulation of CE in macrophages. The number of OxLDL receptors in monocyte-derived macrophages may be one of the causes of variable levels of foam cell formation in atherosclerotic lesions of subjects with similar levels of common risk factos, such as hypercholesterolemia.

Secondly, we demonstrated a significant contribution of CD36 as an OxLDL receptor in vitro. Based on the competition with OKM5 and the difference in the capacity of binding or uptake between CD36-deficient and control macrophages, CD36 appeared to account for at least $40 \%$ of the OxLDL uptake (Figs. 3-5). Although CD36 was found to contribute to a significant part of OxLDL metabolism, CD36-deficient macrophages retained an $\sim 50 \%$ capacity for OxLDL binding and uptake, suggesting that receptors other than CD36 may also play a significant role in OxLDL metabolism. Arai et al. (13) and Sparrow et al. (14) suggested heterogeneity among OxLDL and AcLDL receptors. Other than CD36, the AcLDL receptor which is the so-called scavenger receptor identified by Kodama et al. (7), or SR-B1, which has recently been cloned as a receptor for OxLDL (37), or the $94-97-\mathrm{kD}$ receptor described by Ottnad et al. (38) may be involved in the remaining OxLDL uptake in monocyte-derived macrophages (Fig. 5).

Thirdly, we have shown that OxLDL is degraded through CD36, since a difference in the degradation of OxLDL can be observed between the macrophages from CD36 deficiency and normal controls. OKM5 inhibited the degradation of OxLDL, supporting the hypothesis that OxLDL is degraded through CD36. In our unpublished experiments, we transfected CD36 cDNA to 293T cells and observed the cell association and degradation of ${ }^{125} \mathrm{I}-\mathrm{OxLDL}$. We found that OxLDL was degraded through CD36 in these transfected cells. Furthermore, the degradation was partially, but significantly inhibited by $100 \mu \mathrm{M}$ chloroquine. These findings confirm that OxLDL is degraded through CD36 and that some part of the degradation of OxLDL may occur in the lysosomes.

In CD36-deficient macrophages, AcLDL did not inhibit the cell association of OxLDL to the level of the inhibition by unlabeled OxLDL (Fig. 5). These data may suggest the presence of specific receptors which bind only OxLDL, but not AcLDL. In contrast with OxLDL cell association, AcLDL cell association was competed by OxLDL to the same extent as AcLDL (Fig. 6), suggesting that there may be no specific receptors for AcLDL in human monocyte macrophages, although Arai et al. (13) suggested the presence of a specific receptor for AcLDL which binds only to AcLDL in mouse peritoneal macrophages, but not to OxLDL.

We observed that the cell association of AcLDL was reduced by $54 \%$ in CD36 deficiency compared with that in control macrophages. These data might suggest that AcLDL binds to CD36. Although OKM5 did not compete with the cell association of AcLDL, OKM5 probably will not compete with the binding sites for AcLDL. Controversy exists on the ligand specificity for CD36. Endemann et al. (27) showed that CD36 does not bind to AcLDL, while Anton et al. (37) reported that CD36 actually binds to AcLDL. The difference in the results of these studies may be related to the character of the cells undergoing transfection. In our unpublished observations using transfected 293T cells, AcLDL did not bind to CD36. A possible explanation for these discrepancies is that the binding of AcLDL to CD36 may need the involvement of other factors, or the expressed CD36 may exist in different forms among the transfected cells.

In our experiments, both monocytes and macrophages expressed CD36. Is the role of CD36 the same between monocytes and macrophages in vivo? Previous studies have shown that CD36 may play a role in monocytes adhesion to collagen or thrombospondin. Therefore, as suggested by Endemann et al. 
(27), CD36 could play a role in atherogenesis independent of and in addition to its potential role in foam cell formation.

Will a deficiency of CD36 increase or decrease susceptibility to atherogenesis? Our subjects with CD36 deficiency currently do not show any signs or symptoms of premature atherosclerosis, however the small number of patients available with this rare disorder precludes any firm conclusions. A significant decrease in the rate of uptake of OxLDL by arterial macrophages should slow the development of macrophage-derived foam cells and thus the rate of progression of fatty streaks. From this point of view, a deficiency in CD36 might be antiatherogenic. On the other hand, as has been pointed out (39), failure to take up OxLDL, which is cytotoxic and a growth factor for smooth muscle cells and prothrombotic, might have quite opposite effects. Studies in transgenic mice overexpressing CD36 or deficient in CD36 may be necessary to resolve this complex issue.

In summary, we have presented data suggesting that CD36 on human monocyte-derived macrophages can account for up to $40 \%$ of the binding and uptake of OxLDL under the in vitro conditions used. We therefore suggest that CD36 may contribute to foam cell formation under in vivo conditions. However, when we predict the quantitative role of CD36 in the uptake of OxLDL by arterial macrophages on the basis of these in vitro studies, a careful interpretation must be made. For example, the absolute rate of degradation observed here was low compared, for example, to that in mouse peritoneal macrophages (13), suggesting that the rate of degradation may be much greater even in human macrophages in the vessel wall than in vitro because of the phenotypic shifts. Therefore, the relative contribution of CD36 in vivo may be difficult to predict and will depend upon the extent to which conditions in the artery wall induce the expression of several receptors that are known to bind OxLDL $(15,27,37,38,40)$. Studies of the expression of these receptors in developing lesions (e.g., in situ hybridization) will be needed to evaluate this issue.

\section{Acknowledgments}

We are grateful to Dr. Kazuo Tsubaki (Department of Medicine, Kinki University Hospital) and Dr. Nobuo Nagao (Osaka Red Cross Blood Center) for providing the materials of CD36-deficient subjects.

This work was supported in part by grants-in-aid for Scientific Research from the Ministry of Education, Science, and Culture of Japan, and a Grant for Primary Hyperlipidemia from the Japanese Ministry of Health and Welfare.

\section{References}

1. Gerrity, R. G. 1981. The role of the monocyte in atherogenesis. I. Transition of blood-borne monocytes into foam cells in fatty lesions. Am. J. Pathol. 103:181190.

2. Faggiotto, A., R. Ross, and L. Harker. 1984. Studies of hypercholesterolemia in the nonhuman primate I. Changes that lead to fatty streak formation. Arteriosclerosis. 4:323-340.

3. Schaffner, T., K. Taylor, J. Bartucci, K. Fischer-Dzoga, J. H. Beeson, S. Glagov, and R. W. Wissler. 1980. Arterial foam cells with distinctive immunomorphologic and histochemical features of macrophages. Am. J. Pathol. 100:57-80.

4. Takahashi, K., M. Naito, T. Kodama, H. Suzuki, T. Mori, and A. Matsumoto. 1992. Expression of macrophage scavenger receptors in various human tissues and atherosclerotic lesions. Clin. Biochem. 25:365-368.

5. Goldstein, J. L., Y. K. Ho, S. K. Basu, and M. S. Brown. 1979. Binding site on macrophages that mediates uptake and degradation of acetylated low density lipoprotein, producing massive cholesterol deposition. Proc. Natl. Acad. Sci. USA. 76:333-337.
6. Kodama, T., P. Reddy, P. C. Kishimoto, and M. Krieger. 1988. Purification and characterization of a bovine acetyl low density lipoprotein receptor. Proc. Natl. Acad. Sci. USA. 85:9238-9242.

7. Kodama, T., M. Freeman, L. Rohrer, J. Zabrewcky, P. Matsudaira, and M. Krieger. 1990. Type I macrophage scavenger receptor contains a-helical and collagen-like coiled coils. Nature (Lond.). 343:531-535.

8. Henriksen, T., E. M. Mahoney, and D. Steinberg. 1981. Enhanced macrophage degradation of low density lipoprotein previously incubated with cultured endothelial cells: recognition by receptors for acetylated low density lipoproteins. Proc. Natl. Acad. Sci. USA. 78:6499-6503.

9. Steinbrecher, U. P., S. Parthasarathy, D. S. Leake, J. L. Witztum, and D. Steinberg. 1984. Modification of low density lipoprotein by endothelial cells. Proc. Natl. Acad. Sci. USA. 81:3883-3887.

10. Carew, T. E., D. C. Schwenke, and D. Steinberg. 1987. An antiatherogenic effect of probucol unrelated to its hypocholesterolemic effect: evidence that antioxidants in vivo can selectively inhibit low density lipoprotein degradation in macrophage-rich fatty streaks slowing the progression of atherosclerosis in the WHHL rabbit. Proc. Natl. Acad. Sci. USA. 84:7725-7729.

11. Kita, T., Y. Nagano, M. Yokode, K. Ishii, N. Kume, A. Ooshima, S. Yoshida, and C. Kawai. 1987. Probucol prevents the progression of atherosclerosis in Watanabe heritable hyperlipidemic rabbit, an animal model for familial hypercholesterolemia. Proc. Natl. Acad. Sci. USA. 84:5928-5931.

12. Palinski, W., M. E. Rosenfeld, S. Yla-Herttuala, G. C. Gurtner, S. S. Socher, S. W. Butler, S. Parthasarathy, T. E. Carew, D. Steinberg, and J. L. Witztum. 1989. Low density lipoprotein undergoes oxidative modification in vivo. Proc. Natl. Acad. Sci. USA. 86:1372-1376.

13. Arai, H., T. Kita, M. Yokode, S. Narumiya, and C. Kawai. 1989. Multiple receptors for modified low density lipoproteins in mouse peritoneal macrophages; different uptake mechanisms for acetylated and oxidized low density lipoproteins. Biochem. Biophys. Res. Commun. 159:1375-1382.

14. Sparrow, C. P., S. Parthasarathy, and D. Steinberg. 1989. A macrophage receptor that recognizes oxidized low density lipoprotein but not acetylated low density lipoprotein. J. Biol. Chem. 264:2599-2604.

15. Stanton, L. W., R. T. White, C. M. Bryant, A. A. Protteer, and G. Endemann. 1992. A macrophage Fc receptor for IgG is also a receptor for oxidized low density lipoprotein. J. Biol. Chem. 267:22446-22451.

16. Greenwalt, D. E., R. H. Lipsky, C. F. Ockenhouse, H. Ikeda, N. N. Tandon, and G. A. Jamieson. 1992. Membrane glycoprotein CD36: a review of its roles in adherence, signal transduction and transfusion medicine. Blood. 80:1105-1115.

17. Savil, J., N. Hogg, and C. Haslett. 1992. Thrombospondin cooperates with CD36 and the vitronectin receptor in macrophage recognition of neutrophils undergoing apoptosis. J. Clin. Invest. 90:1513-1522.

18. McKeown, L., M. Vail, W. Kramer, K. Hansmann, and H. Gralnick. 1994. Platelet adhesion to collagen in individuals lacking glycoprotein IV. Blood. 83:2866-2871.

19. Oquendo, P., E. Hundt, J. Lawler, and B. Seed. 1989. CD36 directly mediates cytoadherence of plasmodium falciparum parasitized erythrocytes. Cell. 58:95-101.

20. Tandon, N. N., U. Kralisz, and G. A. Jamieson. 1989. Identification of glycoprotein IV (CD36) as a primary receptor for platelet-collagen adhesion. $J$. Biol. Chem. 264:7576-7583.

21. Ikeda, H., T. Mitani, M. Ohnuma, H. Haga, S. Ohtsuka, T. Kato, M. Nakase, and S. Sekiguchi. 1989. A new platelet-specific antigen, $\mathrm{Nak}^{\mathrm{a}}$, involved in the refractoriness of HLA-matched platelet transfusion. Vox Sang. 57:213217.

22. Tomiyama, Y., H. Take, H. Ikeda, T. Mitani, T. Furubayashi, H. Mizutani, N. Yamamoto, N. Tandon, S. Sekiguchi, G. A. Jamieson, et al. 1990. Identification of the platelet-specific alloantigen, $\mathrm{Nak}^{\mathrm{a}}$, on platelet membrane glycoprotein IV. Blood. 75:684-687.

23. Take, H., H. Kashiwagi, Y. Tomiyama, S. Honda, Y. Honda, H. Mizutani, T. Furubayashi, T. Karasuno, T. Nishiura, Y. Kanayama, et al. 1993. Expression of GPIV and $\mathrm{Nak}^{\mathrm{a}}$-negative subjects whose platelets lack GPIV and $\mathrm{Nak}^{\mathrm{a}}$ antigen on monocytes in $\mathrm{Nak}^{\mathrm{a}}$. Br. J. Haematol. 84:387-392.

24. Kashiwagi, H., S. Honda, Y. Tomiyama, H. Mizutani, H. Take, Y. Honda, S. Kosugi, Y. Kanayama, Y. Kurata, and Y. Matsuzawa. 1993. A novel polymorphism in glycoprotein IV (replacement of proline- 90 by serine) predominates in subjects with platelet GPIV. Thromb. Haemostas. 69:481-484.

25. Kashiwagi, H., Y. Tomiyama, Y. Kosugi, M. Shiraga, R. H. Lipsky, Y. Kanayama, Y. Kurata, and Y. Matsuzawa. 1994. Identification of molecular defects in a subject with type I CD36 deficiency. Blood. 83:3545-3552.

26. Kashiwagi, H., Y. Tomiyama, S. Honda, S. Kosugi, M. Shiraga, N. Nagao, S. Sekiguchi, Y. Kanayama, Y. Kurata, and Y. Matsuzawa. 1995. Molecular basis of $\mathrm{CD} 36$ deficiency: evidence that a ${ }^{478} \mathrm{C}$-T substitution (proline ${ }^{90}$-serine) in CD36 cDNA accounts for CD36 deficiency. J. Clin. Invest. 95:1040-1046.

27. Endemann, G., L. W. Stanton, K. S. Madden, C. M. Bryant, R. T. White, and A. A. Protter. 1993. CD36 is a receptor for oxidized low density lipoprotein. J. Biol. Chem. 268:11811-11816.

28. Nozaki, S., M. Kubo, H. Sudo, Y. Matsuzawa, and S. Tarui. 1986. The 
role of hepatic triglyceride lipase in the metabolism of intermediate-density lipoprotein-postheparin lipolytic activities determined by a sensitive, nonradioisotopic method in hyperlipidemic patients and normals. Metab. Clin. Exp. 35:53-58.

29. Ishigami, M., S. Yamashita, N. Sakai, T. Arai, K. Hirano, H. Hiraoka, K Kameda, and Y. Matsuzawa. 1994. Large and cholesteryl ester-rich high density lipoproteins in cholesteryl ester transfer protein (CETP) deficiency can not protect macrophages from cholesterol accumulation induced by acetylated low-density lipoproteins. J. Biochem. 116:257-262.

30. Bilheimer, D. W., D. Steinberg, and R. I. Levy. 1972. The metabolism of very low density lipoproteins. I. Preliminary in vitro and in vivo observation. Biochim. Biophys. Acta. 260:212-221.

31. Ueyama, Y., S. Nozaki, K. Yanagi, H. Hiraoka, T. Nakagawa, N. Sakai, S. Jiao, S. Yamashita, and Y. Matsuzawa. 1994. Familial hypercholesterolemialike syndrome with apolipoprotein E-7 associated with marked Achilles tendon xanthomas and coronary artery disease: a report of two cases. J. Intern. Med. 235:169-174.

32. Tomiyama, Y., T. Tsubakio, R. S. Piotrowicz, Y. Kurata, J. C. Loftus, and T. J. Kunicki. 1992. The Arg-Gly-Asp (RGD) recognition site of platelet glycoprotein IIb-IIIa on nonactivated platelets is accessible to high-affinity macromolecules. Blood. 79:2303-2312.

33. Lowry, O. H., N. J. Rosebrough, A. L. Farr, and R. J. Randall. 1951 Protein measurement with the Folin phenol reagent. J. Biol. Chem. 193:265-275.
34. Goldstein, J. L., and M. S. Brown. 1974. Binding and degradation of low density lipoproteins by cultured human fibroblasts. J. Biol. Chem. 249:51535162 .

35. Heider, J. G., and R. L. Boyett. 1978. The picomole determination of free and total cholesterol in cells in culture. J. Lipid Res. 19:514-518.

36. Miyazaki, A., A. T. M. A. Rahim, T. Ohta, Y. Morino, and S. Horiuchi 1992. High density lipoprotein mediates selective reduction in cholesteryl esters from macrophage foam cells. Biochim. Biophys. Acta. 1126:73-80.

37. Acton, S. L., P. E. Scherer, H. F. Lodish, and M. Krieger. 1994. Expression cloning of SR-B1, a CD36-related class B scavenger receptor. J. Biol. Chem. 269:21003-21009.

38. Ottnad, E., S. Parthasarathy, G. R. Sambrano, M. P. Ramprasad, O. Quehenberger, N. Kondratenko, S. Green, D. Steinberg. 1995. A macrophage receptor for oxidized low density lipoprotein distinct from the receptor for acetyl low density lipoprotein: partial purification and role in recognition of oxidatively damaged cells. Proc. Natl. Acad. Sci. USA. 92:1391-1395.

39. Steinberg, D. 1990. Arterial metabolism of lipoproteins in relation to atherogenesis. Ann. NY Acad. Sci. 598:125-135.

40. Freeman, M., Y. Ekkel, L. Rohrer, M. Penman, N. J. Freedman, G. M. Chisolm, and M. Krieger. 1991. Expression of type I and type II bovine scavenge receptors in Chinese hamster overy cells: lipid droplet accumulation and nonreciprocal cross competition by acetylated and oxidized low density lipoprotein. Proc. Natl. Acad. Sci. USA. 88:4931-4935. 